\title{
Exploring the Relationship Between Managerial Cognitive Capabilities and Dynamic Managerial Capabilities
}

\author{
Elnivan Moreira de Souza ${ }^{1} \&$ Sérgio Henrique Arruda Cavalcante Forte ${ }^{2}$ \\ ${ }^{1}$ Department of Business, Christus Univeristy Center, Fortaleza, Brazil \\ ${ }^{2}$ Graduate Program of Business Administration, University of Fortaleza, Fortaleza, Brazil \\ Correspondence: Elnivan Moreira de Souza, Department of Business, Christus University Center, Fortleza-CE, Brazil. \\ Tel: 55-859-8614-9246.
}

Received: February 13, 2021

Accepted: March 20, 2021

Online Published: September 2, 2021

doi:10.5430/ijba.v12n5p1

URL: https://doi.org/10.5430/ijba.v12n5p1

The research is financed by Cearense Foundation to Support Scientific and Technological Development / OGG Academic Solutions.

\begin{abstract}
The micro-foundations research agenda's primary motivation in strategy is to dissect macro-level constructs in terms of actions and organizational members' interactions to the micro-level. This work seeks to evolve the understanding of these micro-foundations to explain the relationship between Managerial Cognitive Capabilities and Dynamic Managerial Capabilities. We conducted a laboratory experiment with a sample of 111 participants, divided into two groups, containing 57 and 54 participants, each one. The results revealed that Sensing Opportunity and Seizing Opportunity, components of the Dynamic Managerial Capability, and the Language and Communication, which are part of the Cognitive Managerial Capability, can be predictive of the ability to Reconfigure Tangible and Intangible Assets. Our research contributes by extending central literature on micro-foundations through an experiment. We empirically show that managerial and cognitive dynamic capabilities can be a preeminent field to improve the comprehension of dynamic capabilities' micro-foundations.
\end{abstract}

Keywords: cognitive capability, managerial capability, laboratory experiments, micro-foundations

\section{Introduction}

The notion of capability holds that variations in performance among firms in the same industry can be explained by differences in their subjacent capabilities (Rahmandad \& Repenning, 2016). Capabilities manifest themselves as a configuration of routines and organizational processes that combine to create a landscape of non-linear performance (Fainshmidt et al., 2019).

One of the first articulations of the role of capabilities in determining competitive outcomes (Dierickx \& Cool, 1989) was that capabilities tend to behave as "stock" or "level" variables, meaning they take time to accumulate (Rahmandad \& Repenning, 2016). Subsequent research has focused almost exclusively on management capability accumulation processes, implicitly assuming that, once a given configuration is achieved, the firm can continue to profit from any associated performance benefits until environmental changes make one or more capabilities obsolete (Rahmandad \& Repenning, 2016).

Dynamic capabilities include the difficult-to-replicate business capabilities necessary to adapt to customer changes and take advantage of new technology opportunities. They also adopt the company's ability to shape the ecosystem it engages, develop new products and processes, and design and implement original business models (Felin et al., 2015; Teece, 2007).

The nature of various grades of dynamic capabilities is identified, and some efforts are made to separate the microfoundations of dynamic capabilities from one's capability (Teece, 2007). Thus, important distinctions are made between organizational and managerial processes, procedures, systems, and structures that underpin each capability class.

The new literature on dynamic capabilities has identified a set of processes and routines recognized as providers of dynamic capabilities micro-foundations (Bendig et al., 2018; Teece, 2007; Felin et al., 2015; Kahn, Daddi, \& Iraldo, 
2020). While turnover may lead to the loss of some skills and small breaks in routines, local adaptation allows the company to rebuild capabilities, according to its managers' ability and cognitive capability (Helfat \& Peteraf, 2015; Schilling, 2018).

Therefore, Helfat \& Peteraf (2015: 836) propose the concept of Managerial Cognitive Capabilities, which is the "capacity of an individual manager to perform one or more mental activities that make up cognition." To explain heterogeneous performance results using this perspective requires understanding the contribution of managers' cognitive capability and their relation to the mechanisms through which capabilities accumulate and how this accumulation may differ between firms.

However, the concept of Managerial Cognitive Capability stands out because the capabilities involve the ability to perform not only physical activities but also mental ones. Thus, this research is guided by the following question: What is the relationship between Managerial Cognitive Capabilities and Dynamic Managerial Capabilities?

Given that the company's dynamic capabilities consist of individual activities, the managers' actions regarding the cognitive aspects remain almost unexplored (Schilke et al., 2018; Huy \& Zott, 2019). However, this research explores the relationship between Managerial Cognitive Capabilities (Helfat \& Peteraf, 2015) and Dynamic Managerial Capabilities (Teece, 2007). We know that there are competing versions of dynamic capability concepts (Peteraf et al., 2013; Duddaby et al., 2019), but this is not our aim in this paper.

This research contributes to the theoretical, empirical, and managerial topics. Theoretically, we enlarge the understanding of Managerial Cognitive Capabilities (Helfat \& Peteraf, 2015). Empirically, we use data collected from management professionals in a laboratory experiment, an unusual method to investigate dynamic capabilities. Our study's results contribute to the managerial subjects since it was possible to demonstrate cognitive and managerial variables' influence as micro-foundations of dynamic capabilities.

Thus, within the scope of the dynamic capabilities, the managerial development must also be thinking in line with the managers' cognitive capabilities. Our research reveals how the interaction between cognitive and managerial activities occurs in the strategic management process, contributing to developing dynamic capabilities' micro-foundations.

\section{Dynamic Managerial Capabilities (DMC)}

Teece (2007) demonstrates that the nature and the micro-foundations of dynamic capabilities can be disaggregated into the ability to sense and shape opportunities and threats, seize opportunities and threats, and reconfigure tangible and intangible assets. The ability to apply capabilities sooner, more shrewdly, and more fortuitously is, in fact, the essence of dynamic capabilities (Wang \& Ahmed, 2007). If a company is a set of resources and capabilities, dynamic resources highlight the transformation processes of products or services that offer superior value to customers; this transformation is undertaken quickly, accurately, and creatively, in line with industry changes.

The common characteristics of dynamic capabilities between firms are identifiable and demonstrate commonalities in key features (Eisenhardt \& Martin, 2000). Wang \& Ahmed (2007), based on empirical results from 1995 to 2005, identified three main components of dynamic capabilities: adaptive capability, absorptive capability, and innovative capability. Since then, research on dynamic capabilities has undergone a transition process, moving from the firm's level to the individual's level (Schilke et al., 2018).

Aggarwal et al. (2017) suggest that a manager's strategic choices during the formative period of a routine development (e.g., defining the organization's exploitation policy) can serve as a critical lever. They enabled companies to develop systematic routines that are differentially adaptable to alternative forms of change in technological development.

Organizational routines have become an increasingly central theoretical construct in the strategy literature because of their close link to their capabilities (Winter, 2003). Consequently, the question of whether and how these routines may change has become important (Feldman \& Pentland, 2003). Routines may reflect managerial efforts to purposefully coordinate individuals' actions, for example, through a combination of standard operating procedures and a descending hierarchy (March \& Simon, 1958).

Therefore, the micro-foundations of dynamic capabilities can provide the necessary elements to refine the understanding of specific aspects of management practice (Barney \& Felin, 2013; Bendig et al., 2018; Felin et al., 2015; Foss \& Pedersen, 2016; Helfat \& Martin, 2015; Hernandez-Perlines, 2018; Huy \& Zott, 2019; Nayak et al., 2019; Teece, 2007; Wollersheim \& Heimeriks, 2016) and its contribution to the improvement of dynamic organizations. From this perspective, Teece (2007) argues that the micro-foundations of the dynamic capabilities are composed of abilities, processes, procedures, organizational structures, decision rules, and distinct disciplines that 
support capabilities for detection, apprehension, and reconfiguration at the corporate level, considering that they are challenging to develop and deploy.

These capabilities can be leveraged to continuously create, extend, upgrade, protect, and maintain the company's unique asset base. For analytical purposes, dynamic managerial capabilities can be disaggregated in capacity: (1) to sense and shape opportunities and threats, (2) seize opportunities, and (3) maintain competitiveness to reconfigure, enhance, match, and protect tangible and intangible assets (Teece, 2007; see Figure 1).

\section{Managerial Cognitive Capabilities (MCC)}

Business success depends on the discovery and development of opportunities (Pezeshkan et al., 2016), the effective combination of internally and externally generated inventions (Hernandez-Perlines, 2018), efficient and effective technology transfer within the company and between different companies (Teece, 2014), protection of intellectual property (Younge et al., 2015), updating business processes, the invention of new commercial models (Warner \& Wäger, 2019), impartial decision-making (Ocasio \& Joseph, 2018), and the scope of protection against imitation and other forms of rival replication (Powell et al., 2006). It also involves forming new "rules of the game" in the global market (Teece, 2007).

All these elements represent the process by which dynamic capabilities occur and how they accumulate over time. Helfat and Peteraf (2015) highlight the aspects related to the role of the organization's strategic managers by proposing the concept of Managerial Cognitive Capabilities. For this research, Managerial Cognitive Capabilities is "the ability of an individual manager to perform automatic and controlled mental activities, which consequences are reflected on strategic changes in business models and firm performance" (Souza \& Forte, 2019, pp. 18).

This definition of cognitive capability directs attention to the activities or functions that cognition performs. The human brain performs many different mental activities, such as Perception and Attention, Problem-solving and Reasoning, Language, Communication, and Social Cognition (Helfat \& Peteraf, 2015). Theoretical studies suggest that Managerial Cognitive Capabilities (Helfat \& Peteraf, 2015) precedes Dynamic Managerial Capabilities (Teece, 2007). The MCC and DMC, despite different theories, inevitably co-occur in practice. However, each cognition type is likely to dominate during various sensing, seizing, and reconfiguring stages.

The studies on cognition of the individual also illustrate the influence of Automatic Mental Processing and Controlled Mental Processing (Kahneman, 2011; Larrick \& Feiler, 2016; Stanovich \& West, 2000). The following sections explore these relationships in more detail.

\section{Establishing the Relationship Between Managerial Cognitive Capabilities and Dynamic Managerial Capabilities}

The following sections establish the possible relationships between Managerial Cognitive Capabilities and Dynamic Managerial Capabilities, detailing their micro-foundations, antecedents, and consequent correspondences. The control variables and the representative constructs of the strategic changes in the dotted squares of Figure 1 are for complementary purposes and, therefore, are explained secondarily, considering their close relationship with the micro-foundations of the dynamic capabilities (Teece, 2007) and dynamic managerial capabilities (Helfat \& Peteraf, 2015).

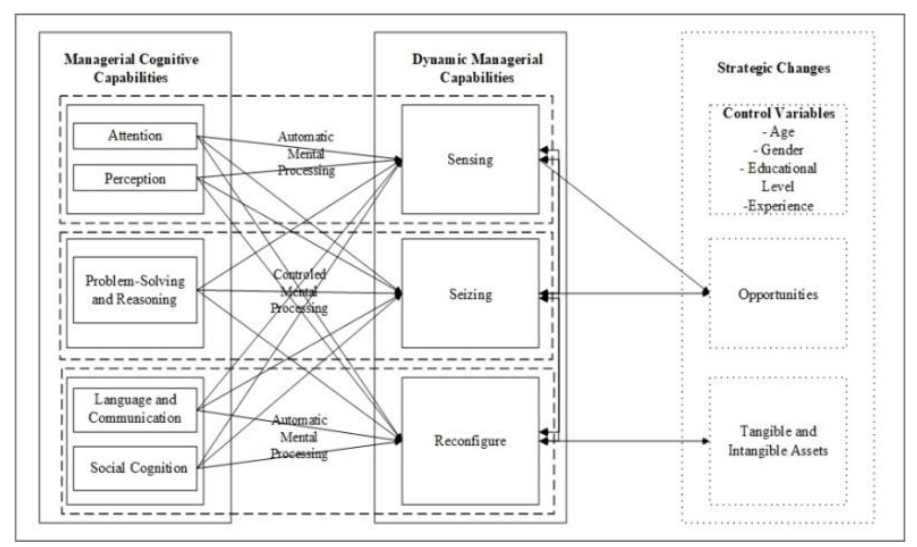

Figure 1. Theoretical-empirical model of managerial cognitive capabilities and dynamic managerial capabilities Source: Prepared by the authors based on Helfat and Peteraf (2015). 


\subsection{Managerial Cognitive Capabilities to Sense Opportunities}

Perception and Attention's cognitive abilities are distributed heterogeneously in individuals (Helfat \& Peteraf, 2015). The phenomenon of "inattentional blindness"-which refers to the lack of attention to an event that occurs during another task's performance - provides an example of attention heterogeneity. Simons and Chabris (1999) found that only $33 \%$ of people realized that a gorilla was crossing a basketball court while watching a basketball game in a classic experiment.

Besides, individuals differ in how well they filter irrelevant information. Similarly, individuals differ in the way they filter out irrelevant information. For example, individuals differ in their performance on a Stroop test. In this test, a person is asked to name the colors of the printed words in which the term for the color (for example, "blue") differs from the color in which the text is printed (Stroop, 1935).

The ability to perceive also varies according to individuals. As noted, experts can navigate information from the domain of their experience more accurately and quickly than non-specialists. Perception also varies across other dimensions. For example, in a study by Stanislaw and Todorov (1999), individuals changed in their "response bias" (a general trend) in the Perception of an ambiguous signal (Bendig et al., 2018). Because Perception depends in part on attention (Ocasio \& Joseph, 2018), the heterogeneity in attention contributes to the heterogeneity in Perception (Helfat \& Peteraf, 2015).

The heterogeneity in Perception and attention is likely to be reinforced by the path dependence of these capabilities. Different prior experiences may lead to heterogeneity among individuals in their ability to perform these mental processes, and this heterogeneity may also be associated with differences between individuals in dependence on automatic versus controlled mental processes (MacLean \& MacIntosh, 2015).

The differences between managers regarding the cognitive capability of attention can distinguish managers who more accurately identify new opportunities and threats (Rahmandad \& Repenning, 2016). Eggers and Kaplan (2009) found that firms whose strategic managers paid more attention to emerging telecommunication technology were more likely to correctly and quickly identify that market's promises. Differences in Perception's cognitive ability can further enhance whether managers recognize standards in the external environment and can interpret this information correctly (Helfat \& Peteraf, 2015). Besides, since practice can improve cognitive abilities, managers who regularly perceive opportunities and threats in the environment can enhance their ability to do so in the future (Teece, 2007).

This heterogeneity of path dependence in managerial cognitive capabilities and their associated sensing capabilities may contribute to heterogeneity in firm performance over time due to the potential for early advantages brought on by a higher perception of emerging opportunities and emerging threats.

\subsection{Managerial Cognitive Capabilities to Seize Opportunities}

The effectiveness of managers in seizing opportunities depends in part on the effectiveness of their underlying cognitive capabilities. As with other cognitive abilities, problem-solving and reasoning are heterogeneous, particularly concerning the thought involved processes. In a review of the psychometric evaluation tests, Brem et al. (2018) documented the heterogeneity among individuals in fluid intelligence measures. Thought arrangements also seem to exhibit performance heterogeneity. For example, Stanovich and West (1997) have found that differences in the ability to avoid bias in assessing an argument's quality, an essential aspect of critical thinking, can be predicted by thinking dispositions even after statistically controlling intelligence. In related work, Frederick (2005, pp. 28-29) found substantial heterogeneity independence on controlled versus automatic processing.

Managers with superior thinking and problem-solving skills are likely to have more significant potential to design more effective business models and make smarter investment decisions (Helfat \& Peteraf, 2015), taking better advantage of opportunities. Business models are difficult to change once implemented. Many investment decisions are hard to reverse, as well. As a result, managerial decisions help explain the relationship between managerial decisions, strategic change, and organizational performance (Helfat \& Martin, 2015).

Thus, heterogeneity in cognitive skills for problem-solving and reasoning can lead to heterogeneity in long-term investments and business models, leading to persistent differentials performance between organizations according to their ability to seize opportunities.

\subsection{The Role of Managerial Cognitive Capabilities in Reconfiguration and Asset Orchestration}

In rapidly changing environments, the ability to detect the need to reconfigure the company's asset structure and carry out the necessary internal and external transformation is highly valued (Birkinshaw et al., 2016). This transformation requires constant vigilance of markets and technologies and a willingness to adopt best practices. The 
ability to reconfigure and transform is a learned organizational skill. The ability to gauge change requirements and make the necessary adjustments depends on diagnosing the environment, evaluating markets and competitors, and rapidly performing reconfigurations and transformations before the competition (Teece and Pisano, 1994).

Sensing and seizing new opportunities can lead to business growth and profit. The third stage of the dynamic capabilities' triad involves maintaining growth and profitability by improving, combining, and reconfiguring the organization's assets - its resources and capabilities. Teece (2007) described this third stage to the use of the term "reconfiguration," whose focus is established on organizational-level phenomena. However, strategic management's role is no less important, as Helfat et al. (2009) clarify in their discussion of "asset orchestration" by strategic managers.

Asset orchestration refers to the selection, configuration, alignment, and modification of tangible and intangible assets (Helfat et al., 2009). Adapting to change in the external environment often requires the enhancement or change of strategic assets through innovation and organizational learning (Wang \& Hu, 2020) and the acquisition of new assets (Wu et al., 2016). In addition, the adaptation of strategic assets throughout the organization implies the integration, recombination, and reconfiguration of these assets (Helfat et al., 2009). This coordinated adaptation is necessary to maintain the strategic fit between organizational assets as conditions change, which may be a factor in sustaining competitive advantage (Peteraf \& Reed, 2007).

Asset reconfiguration depends on strategic managers' ability to persuade others in their organization to undertake new gumptions. Language can be used to communicate broad goals to promote alignment between disparate parts of an organization (Jalonen et al., 2018). The communication style of strategic managers and how they communicate the vision of the organization can inspire employees, encourage initiative, and drive business growth (Baum et al., 1998). Managerial language use, such as through impromptu speech, word flow, and articulation in the conversation, can affect the worker's response to change initiatives.

Social cognitive includes the ability to understand others' points of view and, thus, provide the potential to influence others' behavior as well (Schilling, 2018). Strategic managers' social cognitive capabilities can enable them to influence organizational members to promote asset reconfiguration in at least two ways (Helfat \& Peteraf, 2015). First, these capabilities can help managers foster cooperation, often associated with trust among members of the organization (Bendig et al., 2018). Second, social cognitive capabilities may also be important in managing power relations among organizational members (Krackhardt, 1990), which is important in overcoming organizational inertia and barriers to change (Macmillan \& Guth, 1985).

Coordinated asset matching and overcoming resistance to change can benefit from the dynamic management capabilities for reconfiguration. These dynamic capabilities are likely to depend on managers' cognitive capacities for language and communication and social cognition.

\subsection{The Role of Controlled and Automatic Mental Processing in Cognitive and Managerial Dynamic Capabilities}

Research in psychology and related fields distinguishes two manners of mental processing. The Mental Processing of System 1, predominantly automatic, and the Mental Processing of System 2 referred to in the literature as "controlled," "deliberative," or an "executive function" (Kahneman, 2011; Stanovich \& West, 2000).

Stanovich and West (2000) listed the main differences between the two systems. System 1 is characterized as an automatic, mostly unconscious, and relatively undemanding computational capacity. Thus, it combines automation and heuristic processing properties since these constructs have been discussed several times in the literature (Stanovich \& West, 2000). These properties characterize what Levinson (1995) called interactional intelligence-a system composed of the mechanisms that support Grice's (1975) communication theory since it depends on the attribution of intention. This system aims to model other minds to read intent and make rapid interaction movements based on modeled intentions (Stanovich \& West, 2000). Automatic mental processing occurs in situations that demonstrate repetitive or automated tasks such as locking the door before leaving or changing gears. These actions do not require the use of more elaborate reasoning; that is, one does not need to stop and think to remember how to drive one's car.

System 2 covers the analytical intelligence processes traditionally studied by information processing theorists to discover the computational components underlying intelligence (Stanovich \& West, 2000). System 2, understood as being unique to the human being and responsible for the decontextualized abstract thinking capacity (Evans \& Frankish, 2009), represents a slower, more conscious, and flexible information processing system that can act, for example, in the realization of calculations during a math exercise.

For this research, the most crucial difference between the two systems is that they tend to lead to different kinds of 
interpretations of tasks. The interpretations triggered by System 1 are highly contextualized, personalized, and socialized. They are driven by considerations of relevance and aim to infer conversational intentionality even in situations devoid of conversational characteristics (Levine et al., 2017). The precedent of these mechanisms leads to what has been termed the fundamental computational bias of human cognition (Stanovich, 1999) - the tendency for automatic contextualization of problems. In contrast, the more controlled processes of System 2 serve to decontextualize and depersonalize the problems. It can deal with problems without social content and is not controlled by attributing intentionality to the search for conversational relevance.

\section{Managerial Cognitive and Managerial Dynamic Capabilities: The Experiment}

We follow the recommendations of Salvato and Rerup (2011) and Winter (2003) to use an experimental design (Berkowitz \& Donnerstein, 1982). Experiments have several significant benefits. First, experimental research is an excellent way to address causality issues (Bono \& McNamara, 2011). Despite its inherent simplification, experiments represent a suitable and proven method for discovering underlying processes such as dynamic capabilities (Wollersheim \& Heimeriks, 2016). Although the study of dynamic capabilities is expanding rapidly, experimental analyses of dynamic capabilities are still rarely found in the literature (Wollersheim \& Heimeriks, 2016). Therefore, the use of a laboratory experiment seems promising.

Second, laboratory experiments are adequate to address the limitations of studies based on field observations. Specifically, the design proposed in this research does not suffer from problems typical of studies based on real-world data. Such studies typically suffer from either the use of weak measures of dynamic (cognitive and managerial) capability or the inability to determine how operational procedures would have evolved if the degree of dynamic capability had been greater or lesser.

In contrast to studies based on real-world data, this laboratory study allowed us to exert control by exclusively manipulating the variables that define the concepts of cognitive and managerial capabilities, while everything else remains constant. As a result, this experimental design allowed us to make inferences about the dynamic capabilities that complement the existing field studies.

The experiment included two groups, spanning seven sessions, with each session divided into four phases. Each session lasted approximately $150 \mathrm{~min}$ (2.5 hours), totaling $1,050 \mathrm{~min}$ (17.5 hours) of the experiment (see Table 1$)$. In phase I, the participants were submitted to the Stroop test (1935) to evaluate their Attention level. In phase II, the participants participated in the Perception test of Andrade et al. (2012). In phase III, the participants performed the Stanford-Binet Problem-Solving and Reasoning test (Becker, 2003). Finally, in phase IV, participants answered a questionnaire to assess Language and Communication skills (Dunbar et al., 2006) and Social Cognition (Richmond \& McCroskey, 1990). In total, 2,442 test pages were generated for tabulation and analysis, as each of the 111 participants responded 22 test pages.

Participants were divided into two groups. In group 1, all the tests (phases I, II, and III) were performed before the beginning of the management simulation stage. In group 2, the tests were intercalated between the decision-making, four for each group. Phase IV was always conducted at the end of the sessions. It consisted of an evaluation in which each participant judged the Language and Communication skills (Dunbar et al., 2006) and Social Cognition (Richmond \& McCroskey, 1990) of the activity partners.

This experiment serves as an important step to generate a better understanding of dynamic capabilities' characteristics after events (internal and external) in physical and mental activities within organizations. Although group analysis in a clearly defined routine development task captures only some of the features of a real-world scenario,

Weber and Camerer (2003, pp. 404) stress that are using experiments, considered as simplified re-creations of complex real-world phenomena, can help understand the underlying processes in several phenomena, including dynamic capabilities. The experimental design proposed here intends to make a fundamental contribution to the literature on dynamic capabilities in a field that has so far presented little empirical evidence using this method (Stefano \& Gutierrez, 2018; Wollersheim \& Heimeriks, 2016).

\subsection{Laboratory Expeiment}

\subsubsection{Experimental Design, Data Collection and Analysis}

This laboratory experiment is based on Conlon and Parks (1990) and Kunc and Morecroft (2010) studies. It involves using business games that simulate a simplified decision-making environment in which participants play the managers' role. We used the OGG Pem management simulator, a web platform nationally known and used by several 
business schools and companies throughout Brazil.

The data were collected from September to December 2018, through seven sessions of business games applied to professionals in the management area who were recruited from four business schools in the city of Fortaleza, in the northeast of Brazil, here called A, B, C, and D (Table 1).

The participants were organized in pairs for decision-making. Each company was managed by two participants, who had to work in a team to understand the business, know the variables, and make management decisions that represented the operation of a small manufacturer of wooden chairs. All companies started with the same conditions to control the uncontrolled variables (Stefano \& Gutierrez, 2018).

The complete cycle of decision-making was four rounds. Each round represented three months of operation; in the end, the four rounds represented one year of operations for all companies. At the end of each decision, the Animator (the main author) processed the decisions and presented a ranking in which the companies were classified according to five criteria: (i) to be a leader in the region of leadership (weight 3), (ii) to be among the first three in the region of strong performance (weight 2), (iii) return on assets (weight 4), (iv) level of indebtedness (weight 1), and (v) innovation (weight 3 ). The weights for each criterion were not revealed to the participants.

Table 1. Details of the experiments

\begin{tabular}{llllll}
\hline Group & School & Collection Date & Duration & No. of Participants & Educational level \\
\hline 1 & A & September 22, 2018 & $150 \mathrm{~min}$ & 16 & Graduate \\
\hline 1 & B & October 30, 2018 & $150 \mathrm{~min}$ & 24 & Undergraduate \\
\hline 1 & C & November 06, 2018 & $150 \mathrm{~min}$ & 17 & Undergraduate \\
\hline 2 & B & November 13, 2018 & $150 \mathrm{~min}$ & 22 & Undergraduate \\
\hline 2 & A & November 17, 2018 & $150 \mathrm{~min}$ & 9 & Undergraduate \\
\hline 2 & A & December 03, 2018 & $150 \mathrm{~min}$ & 8 & Undergraduate \\
\hline 2 & D & December 08, 2018 & $150 \mathrm{~min}$ & 15 & Graduate \\
\hline
\end{tabular}

\subsubsection{Procedures and Information About Participants}

Before beginning each of the experiment's seven sessions, the participants received a report with the game's initial conditions. In this document, they had access to information such as installed production capacity, the initial stock of raw material, cost for acquisition and storage of raw material, freight cost, the quantity of finished product stock, staff, minimum salary, and financial cost for loan money from banks. We also provided the income statement for the year and cash flow reports for the last period. Participants had 10 minutes to review the information. Then, everyone was given a login and password to access the simulator.

The first strategic decision involved the choice of regions for leadership and strong performance. They had to choose two from three regions; this decision was also crucial in determining the final performance since one of the managers' objectives was to select the most promising and least competitive regions. In the simulator manual, information about each region could help them choose, for example, population size, number of cities that formed the region, number of industries and trade, demand forecast, and some qualitative information such as culture and tradition. For this stage, the participants had 10 minutes.

In the next step, participants began operating business decisions. Participants in Group 1 performed Attention, Perception, and Rationality tests simultaneously before making decisions. In contrast, Group 2 participants performed the Attention, Perception, and Rationality tests in the intervals between decisions 1, 2, and 3, respectively, as this was one of the manipulations performed in the experiment.

The participants, therefore, had to make four decisions. Between each decision, the time to do so was purposefully reduced. For decision 1, the participants had 40 minutes, decision 2 allowed 20 minutes, decision 3 allowed 10 minutes, and decision 4 allowed only 5 minutes. This time reduction was aimed to analyze the effect of automatic and controlled mental processing (Stanovich \& West, 2000). It is important to remember that participants were not informed about the research question underlying the experiments to avoid influencing their behavior. 


\subsection{Variables of This Study}

\subsubsection{Independent Variables}

Although there are few quantitative studies on dynamic capabilities in the literature (Drnevich \& Kriauciunas 2011; Heimeriks et al., 2012), these studies' measures are not suitable for laboratory data. For this experimental method, we adopted as independent variables: Attention (At), Perception (Per), Problem-Solving and Reasoning (PSR), Language and Communication (LC) and Social Cognition (SC). All of them, except LC and SC, were standardized at values from zero to ten. It is important to emphasize that Attention (At), Perception (Per), and Problem Solving and Rationality (PSR) tests were summarized to avoid having an experiment that was too extensive and discouraged the participants. After applying the pre-test carried out in a regular group of the discipline business game in an undergraduate management course, this procedure was a decision taken by us.

To measure Attention (At), we used Stroop's (1935) color test. This test consists of two tasks, one reading and another color naming. In both, the stimuli are color names presented in incongruent color. Respondents had three minutes to name 60 words. The evaluation consists of verifying the greatest accuracy within the shortest time possible.

We evaluated the Perception (Per) ability using Andrade et al.'s (2012) test. This test consists of a tetra factorial scale originally formed by 20 items that evaluate four dimensions related to visual Perception: the constancy of shape, background figure, position, and spatial relationship. This test was adapted for 10 items. For each correct answer, one point is assigned, and a maximum of 10 points can be reached. Participants had seven minutes to complete this test.

We evaluated the Problem-Solving and Reasoning (PSR) variable using the Stanford-Binet test (Becker, 2003). The test measures five weighted factors and consists of verbal and non-verbal subtests. The five factors tested were knowledge, quantitative reasoning, visual-spatial processing, working memory, and fluid reasoning. The test is originally composed of 60 questions, but we used a short version of 15 questions. Participants had seven minutes to respond.

To measure Language Communication (LC) and Social Cognition (SC), we used Dunbar et al.'s (2006) scale to evaluate communication skills and Richmond and McCroskey's (1990) work to evaluate Social Cognition. In this case, each participant would answer the questionnaire considering the performance of their experiment partner. In all sections, this questionnaire was completed at the end of the experiment sessions so that each participant had sufficient time to evaluate their partner's communication performance.

\subsection{2 (In) Dependent Variables}

We treated the variables Sensing Opportunities (SenOp), Seizing Opportunities (SeiOp), and Reconfigure Tangible and Intangible Assets (RTIA) as dependent and independents to explore the interplay between variables. To evaluate the participants' sensing opportunity ability, we manipulated, in the simulator, the variables raw material price and fixed cost of production. After changing these variables, the researcher asked the participants to respond to a verification questionnaire. In this questionnaire, it was possible to verify if the participant had detected any changes in these variables, treated as dummy variables even though we evaluated whether they sensed the opportunity.

Next, we check for changes in decisions. We expected the following changes: an increase in the purchase volume of raw materials and changes in the product's sale price. Thus, we can see if the participants took advantage of the opportunities we manipulated in the experiment. We also treated the variable seizing opportunity as a dummy; that is, the participant takes advantage or does not seize the opportunity.

In the next step, we evaluate the variable Reconfigure Tangible and Intangible Assets (RTIA). We evaluate the company's assets' resulting impact through the changes in Return on assets (ROA). Since the modifications introduced from the detection and the utilization of opportunities should be reflected in incremental improvements in organizational performance, with ROA (Shareholders' Equity/Total Assets) being the best measure of decisions' assertiveness over the four rounds (Amit \& Schoemaker, 1993). The RTIA was a continuous variable. We processed and analyzed the data with the support of Excel 2010 and the Statistical Package for Social Science (SPSS v.21) software.

\subsection{Sample}

The total sample was distributed in 111 observations in the seven experiment sessions. The sample consisted of 57 men $(51.35 \%)$ and 54 women $(48.65 \%)$, ranging in age from 19 to 53 years, with a mean age of 29.14 years $(\mathrm{SD}=$ 8.46). Participants were randomly assigned to groups $1(\mathrm{~N}=57)$ and $2(\mathrm{~N}=54)$. As for educational level, $38.9 \%$ are attending college, $38.9 \%$ have completed undergraduate courses, and $22.2 \%$ have completed or are pursuing graduate 
courses. All participants have an undergraduate or graduate degree in the area of management. The average time of professional experience was 4.2 years $(\mathrm{SD}=4.5)$.

\section{Results}

\subsection{Analysis of Difference Between Control Groups}

The next step consisted of the t-test between groups 1. Attention, Perception, and Rationality tests were performed before the decision-making and group 2, whose tests were performed in the interval between each of the four decisions they made (see Table 2).

Table 2. Testing of independent samples

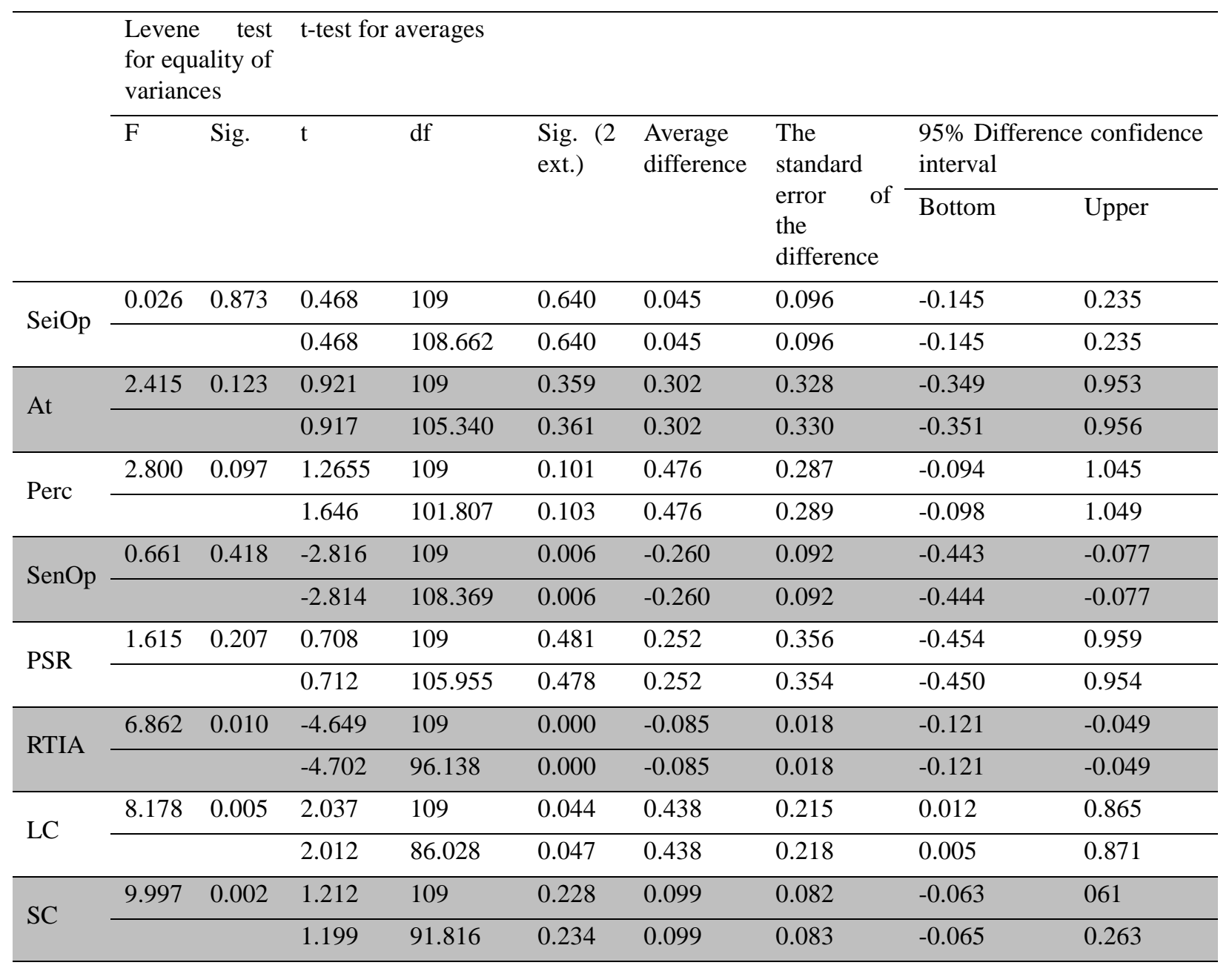

The variables SenOp, RTIA, and LC, presented significance less than 0.05 ; that is, the null hypothesis of equality was rejected. Only these three variables demonstrated significant differences between groups 1 and 2. For the other variables, SeiOp, At, Perc, PSR, and SC, there were no significant differences; therefore, the equality hypothesis was accepted. In the variable SenOp ( $(109)=-2.816, \mathrm{p}<0.05)$, the mean for group 1 was $0.35(\mathrm{SD}=0.481)$, and for group 2 it was $0.61(\mathrm{SD}=0.492)$, that is, the participants who performed the tests between the decisions performed $74.28 \%$ better in seizing opportunities.

The RTIA variable $(\mathrm{t}(109)=-4.649, \mathrm{p}<0.05)$ also presented a higher mean for group $2(\mathrm{M}=0.056542, \mathrm{SD}=$ $0.114146)$ compared to group $1(\mathrm{M}=-0.028634$; $\mathrm{SD}=073326)$, that is, the ability to Reconfigure Tangible and Intangible Assets was $297 \%$ greater for participants in group 2. The LC variable $(\mathrm{t}(109)=2.037 ; \mathrm{p}<0.05)$, revealed greater values for group $1(\mathrm{M}=8.96, \mathrm{SD}=0.8314)$ in relation to group $2(\mathrm{M}=8.528, \mathrm{M}=1.3815)$, with a difference of only $5 \%$. 


\subsection{Exploring the Relationship Between Managerial Cognitive Capabilities and Managerial Dynamic Capabilities}

We performed a new binary logistic regression to verify if the SeiOp, At, Perc, RSP, RTIA, LC, and SC variables are predictive of the Sensing Opportunity (SenOp) ability. The classification table showed that $80.2 \%$ were adequately classified by the model. The model containing SeiOp and LC was significant $[X 2(2)=41.900 ; p<0,05, \mathrm{R} 2$ Nagelkerke $=0.419]$; therefore, Seizing Opportunities (SeiOp) $(\mathrm{OR}=0.078$; CI 95\% $=0.003-0.205)$ and Language and Communication $(\mathrm{LC})(\mathrm{OR}=2.010$; CI $95 \%=1.264-3.197)$ were considered significant predictors. Equation 1 describes this relationship:

$$
P(\text { Sensing Opportunities }- \text { SenOp })=\frac{e^{[(-4.754-2.550 .(\text { SeiOp })+0.698 .(L C)]}}{1+e^{[(-4.754-2.550 .(\text { SeiOp })+0.698 .(L C)]}}
$$

Then, we performed a binary logistic regression to verify if the variables SenOp, At, Perc, RSP, RTIA, LC, and SC are predictors of the ability to Seize Opportunities (SeiOp). We included all the variables in the analysis. The classification table showed that the model adequately classified $91.9 \%$ of the cases. The model containing SeiOp and RTIA was significant [X2 (1) = 91.386; p <0.001, R2 Nagelkerke $=0.749)$; therefore, Sensing Opportunity (OR) (OR $=0.010,95 \% \mathrm{CI}=0.002-0.063)$ and Reconfiguration of Tangible and Intangible Assets $(\mathrm{OR}=3.422,95 \% \mathrm{CI}=$ $30812454,55-3,801)$ were considered significant predictors. Equation 2 describes that this relation is:

$$
P(\text { Seizing Opportunities }- \text { SeiOp })=\frac{e^{[(1.324-4.579 .(\text { SenOp })+28.861 .(\text { RTIA })]}}{1+e^{[(1.324-4.579 .(\text { SenOp })+28.861 .(R T I A)]}}
$$

Finally, we performed a multiple linear regression to verify if the variables SenOp, SeiOp, At, Perc, RSP, LC, and SC were predictive of the ability to reconfigure tangible and intangible assets (RTIA). To do so, we used the stepwise method to select which variables most influence the output set, thus reducing the number of variables to be included in the regression equation (Hair et al., 2015). The model containing SeiOp, SenOp, and At was significant $[F(3,107)$ $=29,964 ; \mathrm{p}<0.001 ; \mathrm{R} 2=0.457$ ], observing the criteria of normality, multicollinearity, and homoscedasticity (Hair et al., 2015).

\subsection{The Influence of Controlled and Automatic Mental Processing}

To evaluate the influence of automatic and controlled mental processing, we used the ROA indicator of the four periods to evaluate the participants' management performance by period and groups. In period 1, the participants had 40 minutes to make the first decision. At this stage, the participants were required to use controlled mental processing. After every decision, the subsequent time to decide was reduced, and as the process became known and repetitive, automatic processing was gaining strength.

\begin{tabular}{|c|c|c|c|c|c|c|c|c|c|}
\hline & \multicolumn{2}{|c|}{$\begin{array}{l}\text { Levene test for } \\
\text { equality } \\
\text { variances }\end{array}$} & \multicolumn{7}{|c|}{$\mathrm{t}$-test for averages } \\
\hline & \multirow[t]{2}{*}{$\mathrm{F}$} & \multirow[t]{2}{*}{ Sig. } & \multirow[t]{2}{*}{$\mathrm{t}$} & \multirow[t]{2}{*}{ df } & \multirow[t]{2}{*}{$\begin{array}{l}\text { Sig. (2 } \\
\text { ext.) }\end{array}$} & \multirow[t]{2}{*}{$\begin{array}{l}\text { Average } \\
\text { difference }\end{array}$} & \multirow{2}{*}{$\begin{array}{l}\text { The } \\
\text { standard } \\
\text { error of the } \\
\text { difference }\end{array}$} & \multicolumn{2}{|c|}{$\begin{array}{l}95 \% \text { Difference } \\
\text { confidence interval }\end{array}$} \\
\hline & & & & & & & & Bottom & Upper \\
\hline \multirow{2}{*}{ ROA1 } & 2.054 & 0.155 & -1.057 & 109 & 0.293 & -0.021 & 0.020 & -0.059 & 0.018 \\
\hline & & & -1.056 & 108.390 & 0.293 & -0.021 & 0.020 & -0.059 & 0.018 \\
\hline \multirow{2}{*}{ ROA2 } & 7.075 & 0.009 & -3.694 & 109 & 0.000 & -0.128 & 0.034 & -0.120 & -0.059 \\
\hline & & & -3.747 & 88.921 & 0.000 & -0.128 & 0.034 & -0.194 & -0.060 \\
\hline \multirow{2}{*}{ ROA3 } & 6.557 & 0.012 & -3.519 & 109 & 0.001 & -0.091 & 0.026 & -0.142 & -0.040 \\
\hline & & & -3.499 & 101.663 & 0.001 & -0.091 & 0.026 & -0.142 & -0.039 \\
\hline \multirow{2}{*}{ ROA4 } & 4.715 & 0.032 & -2.924 & 109 & 0.004 & -0.086 & 0.029 & -0.145 & -0.028 \\
\hline & & & -2.884 & 83.113 & 0.005 & -0.086 & 0.030 & -0.145 & -0.027 \\
\hline
\end{tabular}

Table 3. Testing of independent samples to ROA 
However, we performed a t-test of independent samples which showed that, on average, the companies managed by the participants in group 2 presented better ROAs in periods 2 [ $\mathrm{t}(109)=-3.694 ; \mathrm{P}<0.01], 3$ [t (109) $=-3.519 ; \mathrm{p}$ $<0.01]$, and 4 [t $(109)=-2924 ; \mathrm{P}<0.01]$ (see Tables 3 and 4).

Table 4. Group statistics

\begin{tabular}{llllll}
\hline & GROUP & $\mathrm{N}$ & Average & Standard deviation & $\begin{array}{l}\text { Mean } \\
\text { error }\end{array}$ \\
\hline \multirow{2}{*}{ ROA1 } & group 1 & 57 & -0.028422 & 0.1019906 & 0.0135090 \\
\cline { 2 - 6 } & group 2 & 54 & -0.007749 & 0.1040986 & 0.0141660 \\
\hline \multirow{2}{*}{ ROA2 } & group 1 & 57 & -0.009005 & 0.2223864 & 0.0294558 \\
\cline { 2 - 6 } & group 2 & 54 & 0.118336 & 0.1245492 & 0.0169490 \\
\hline \multirow{2}{*}{ ROA3 } & group 1 & 57 & -0.039216 & 0.1204411 & 0.0159528 \\
\cline { 2 - 6 } & group 2 & 54 & 0.051392 & 0.1499027 & 0.0203992 \\
\hline \multirow{2}{*}{ ROA4 } & group 1 & 57 & -0.043967 & 0.1092863 & 0.0144753 \\
\cline { 2 - 6 } & group 2 & 54 & 0.042179 & 0.1920151 & 0.0261300 \\
\hline
\end{tabular}

\section{Discussion and Managerial Implications}

The participants in group 1 underwent psychological tests that required a lot of their mental capacity before starting to manage the business in the simulator. This mental effort may have influenced their ability to Seize Opportunity (SeiOp), which may have impacted the business's performance. As their ability to Reconfigure Tangible and Intangible Assets (RTIA) was also substantially affected, representing a mean ROA that was nearly three times higher in group 1, who performed the psychological tests before decisions, than group 2, who performed the tests between decisions.

Based on the tests carried out in this sample, we concluded that mental activities influence the ability to seize opportunities and reconfigure tangible and intangible assets. However, it is still not possible to affirm how the impact of neuropsychological constructs, such as Attention, Perception, Rationality and Language, and Communication, occurs to improve Cognitive Dynamic Capability.

In the first regression, the Seizing Opportunity (SeiOp) and Language and Communication (LC) variables emerging as dependents of the variable Sensing Opportunity (SenOp). They revealed that these abilities are relevant to the extent that it is possible to alert managers that Language and Communication, as part of the Managerial Cognitive Capabilities and Seizing Opportunity, as a component of the Dynamic Managerial Capabilities, contribute to the performance of the Sensing Opportunity activity.

In the second regression, we found that the ability to Sense Opportunity (SenOp) may depend on the ability to Reconfigure Tangible and Intangible Assets (RTIA). These results show that there is a correlation between the variables that make up the Dynamic Managerial Capabilities. Still, it was not possible to identify the relationship with the variables that comprise Managerial Cognitive Capabilities.

Finally, the multiple linear regression demonstrated that the ability to Reconfigure Tangible and Intangible Assets (RTIA) might depend on the Managerial Dynamic Capabilities of Seizing Opportunity and Sensing Opportunity and the Managerial Cognitive Capabilities of Attention.

Strategy studies have demonstrated the importance of these three variables (Helfat \& Peteraf, 2015; Kahn, Daddi, \& Iraldo, 2020; Kunc \& Morecroft, 2010; Teece, 2007). The ability to sense opportunities by analyzing objective data goes beyond organizational memory systems (Walsh \& Ungson, 1991) or performance data (Ansoff, 1980). Instead, it requires managers to acquire widely cognitive horizons that focus on the micro-level despite the macro-level (Suddaby et al., 2020).

We observed another pattern in Figure 2 because the overall ROA of group 1 was below zero in the four periods, while the ROA of group 2 started negative in the first period but remained positive over the following three periods. In both groups, there was a marked evolution in the transition from period 1 to period 2 and a slightly more pronounced decrease in the transition between periods 2 and 3. In period 4, the ROA for group 1 decreased while 
group 2 experienced a small improvement.

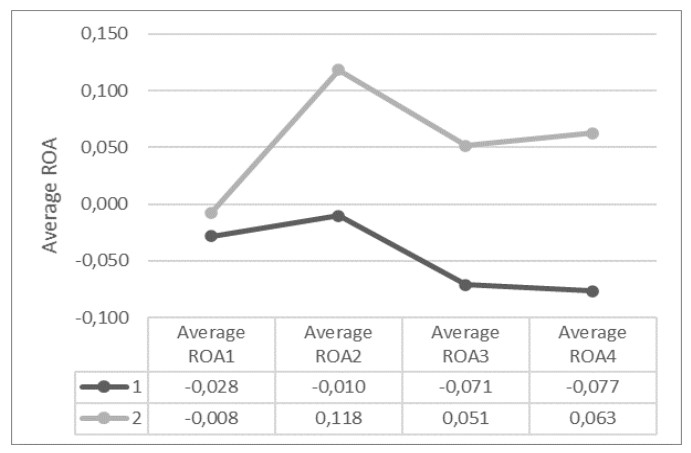

Figure 2. ROA evolution by period

Note that for ROA1, associated with controlled processing, there was no statistical difference between the groups. At the beginning of the simulation session, there was still no influence on the mental effort to perform the psychological tests of Attention, Perception, and Rationality. Therefore, from period 2 onwards, better performance can be seen for the participants who performed the tests between the decisions. Considering that they needed a few minutes of concentration before making the decisions, it is possible to infer that this brief concentration to carry out the Attention, Perception, and Rationality tests may have contributed to the improvement of the companies' overall performance (Kahneman, 2011; Stanovich \& West, 2000). With practice, there was an evolution in the performance of the companies.

\section{Conclusions}

The micro-foundations drive in macro-management does intend to link with more micro disciplines such as psychology and organizational behavior. It also features a single set of questions, assumptions, theoretical mechanisms, and independent/dependent variables that complement the focus of micro disciplines (Felin et al., 2015). Sensing a possible change in the invisible thread of environmental change requires decision-makers to develop distinct cognition forms that improve management's reasoning ability (Suddaby et al., 2020).

Research-based on the control groups' divisions has brought unprecedented and relevant results to this field of research. Group 2 participants performed better at Seizing Opportunities, which impacted the ability to Reconfigure Tangible and Intangible Assets, directly reflecting a better performance for companies managed by these participants.

The regressions analysis has shown that Sense and Seize Opportunities' abilities, belonging to the Managerial Dynamic Capability, and the Attention, belonging to the Cognitive Dynamic Capability, can be predictive of the ability to Reconfigure Tangible and Intangible Assets. Therefore, it was possible to find a partial influence of the Cognitive Dynamic Capability on the Managerial Dynamic Capability.

The evaluation of the influence of controlled and automatic mental processing indicated that the companies managed by the participants of group 2 achieved better performance, demonstrating that the use of cognitive tests can improve the quality of decisions. Practically, a greater emphasis is placed on the development of cognitive abilities in strategic management processes.

We recommend that future studies use other Attention, Perception, Problem Solving and Rationality, and Social Cognition tests. We also suggest using continuous variables to evaluate Sense and Seize Opportunities' ability, considering that dichotomous variables were a limiting factor for this research. Unfortunately, we did not find similar studies to make comparisons confirm or refuse our results.

\section{References}

Aggarwal, V. A., Posen, H. E., \& Workiewicz, M. (2017). Adaptive capacity to technological change: A

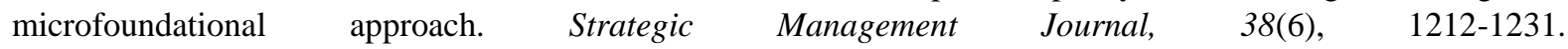
https://doi.org/10.1002/smj.2584

Amit, R., \& Schoemaker, P. J. (1993). Strategic assets and organizational rent. Strategic Management Journal, 14(1), 33-46. https://doi.org/10.1002/smj.4250140105 
Andrade, S. M., Dias, M. M. C. D. B. D. S., Oliveira, E. A. D., Locks Neto, F., Nogueira, R. M. T. B. L., \& Santos, N. A. D. (2012). Construção e evidências psicométricas de uma escala de avaliação da percepção visual. Psicologia: Reflexão e Crítica, 25(1), 21-29. https://doi.org/10.1590/S0102-79722012000100004

Barney, J. A. Y., \& Felin, T. (2013). What are microfoundations?. Academy of Management Perspectives, 27(2), 138-155. https://doi.org/10.5465/amp.2012.0107

Baum, J. R., Locke, E. A., \& Kirkpatrick, S. A. (1998). A longitudinal study of the relation of vision and vision communication to venture growth in entrepreneurial firms. Journal of Applied Psychology, 83(1), 43-54. https://doi.org/10.1037/0021-9010.83.1.43

Becker, K. A. (2003). History of the Stanford-Binet intelligence scales: Content and psychometrics (Stanford-Binet Intelligence Scales, Fifth Edition Assessment Service Bulletin No. 1). Itasca, IL: Riverside Publishing.

Bendig, D., Strese, S., Flatten, T. C., Da Costa, M. E. S., \& Brettel, M. (2018). On micro-foundations of dynamic capabilities: A multi-level perspective based on CEO personality and knowledge-based capital. Long Range Planning, 51(6), 797-814. https://doi.org/10.1016/j.lrp.2017.08.002

Berkowitz, L., \& Donnerstein, E. (1982). External validity is more than skin deep: Some answers to criticism of laboratory experiments. American Psychologist, 37(3), 245-257.

Birkinshaw, J., Zimmermann, A., \& Raisch, S. (2016). How do firms adapt to discontinuous change? Bridging the dynamic capabilities and ambidexterity perspectives. California Management Review, 58(4), 36-58. https://doi.org/10.1525/cmr.2016.58.4.36

Bono, J. E., \& McNamara, G. (2011). Publishing in AMJ-Part 2: Research design. Academy of Management Journal 54(4), 657-660. https://doi.org/10.5465/amj.2011.64869103

Brem, A. K., Almquist, J. N. F., Mansfield, K., Plessow, F., Sella, F., Santarnecchi, E., ... Yeung, N. (2018). Modulating fluid intelligence performance through combined cognitive training and brain stimulation. Neuropsychologia, 118, 107-114. https://doi.org/10.1016/j.neuropsychologia.2018.04.008

Conlon, E. J., \& Parks, J. M. (1990). Effects of monitoring and tradition on compensation arrangements: An experiment with principal-agent dyads. Academy of Management Journal, 33(3), 603-622. https://doi.org/10.5465/256583

Dierickx, I., \& Cool, K. (1989). Asset stock accumulation and sustainability of competitive advantage. Management Science, 35(12), 1504-1511. https://doi.org/10.1287/mnsc.35.12.1504

Drnevich, P. L., \& Kriauciunas, A. P. (2011). Clarifying the conditions and limits of the contributions of ordinary and dynamic capabilities to relative firm performance. Strategic Management Journal, 32(3), 254-279. https://doi.org/10.1002/smj.882

Dunbar, N. E., Brooks, C. F., \& Kubicka-Miller, T. (2006). Oral communication skills in higher education: Using a performance-based evaluation rubric to assess communication skills. Innovative Higher Education, 31(2), 115. https://doi.org/10.1007/s10755-006-9012-x

Eggers, J. P., \& Kaplan, S. (2009). Cognition and renewal: Comparing CEO and organizational effects on incumbent adaptation to technical change. Organization Science, 20(2), 461-477. https://doi.org/10.1287/orsc.1080.0401

Eisenhardt, K. M., \& Martin, J. A. (2000). Dynamic capabilities: what are they?. Strategic Management Journal, 2l(10-11),

1105-1121. https://doi.org/10.1002/1097-0266(200010/11)21:10/11<1105::AID-SMJ133>3.0.CO;2-E

Fainshmidt, S., Wenger, L., Pezeshkan, A., \& Mallon, M. R. (2019). When do dynamic capabilities lead to competitive advantage? The importance of strategic fit. Journal of Management Studies, 56(4), 758-787. https://doi.org/10.1111/joms.12415

Feldman, M. S., \& Pentland, B. T. (2003). Reconceptualizing organizational routines as a source of flexibility and change. Administrative Science Quarterly, 48(1), 94-118. https://doi.org/10.2307/3556620

Felin, T., Foss, N. J., \& Ployhart, R. E. (2015). The microfoundations movement in strategy and organization theory. Academy of Management Annals, 9(1), 575-632. https://doi.org/10.5465/19416520.2015.1007651

Foss, N. J., \& Pedersen, T. (2016). Microfoundations in strategy research. Strategic Management Journal, 36(13), E22-E34.

Frankish, K., \& Evans, J. S. B. (2009). In two minds: Dual processes and beyond. Oxford: Oxford University Press. 
Frederick, S. (2005). Cognitive reflection and decision making. Journal of Economic Perspectives, 19(4), 25-42. https://doi.org/10.1257/089533005775196732

Grice, H. (1975). Logic and conversation - in Syntax and Semantics (Vol. 3, pp. 41-58). New York: Academic Press.

Hair, Jr. J. F., Wolfinbarger, M., \& Money, A. H. (2015). Essentials of business research methods. London: Routledge.

Heimeriks, K. H., Schijven, M., \& Gates, S. (2012). Manifestations of higher-order routines: The underlying mechanisms of deliberate learning in the context of postacquisition integration. Academy of Management Journal, 55(3), 703-726. https://doi.org/10.5465/amj.2009.0572

Helfat, C. E., \& Martin, J. A. (2015). Dynamic managerial capabilities: Review and assessment of managerial impact on strategic change. Journal of Management, 41(5), 1281-1312. https://doi.org/10.1177/0149206314561301

Helfat, C. E., \& Peteraf, M. A. (2015). Managerial cognitive capabilities and the microfoundations of dynamic capabilities. Strategic Management Journal, 36(6), 831-850. https://doi.org/10.1002/smj.2247

Helfat, C. E., Finkelstein, S., \& Mitchell, W. (2009). Dynamic capabilities: Understanding strategic change in organizations. Malden: Blackwell Publishing.

Hernandez-Perlines, F. (2018). Moderating effect of absorptive capacity on the entrepreneurial orientation of international performance of family businesses. Journal of Family Business Management, 8(1), 58-74. https://doi.org/10.1108/JFBM-10-2017-0035

Huy, Q., \& Zott, C. (2019). Exploring the affective underpinnings of dynamic managerial capabilities: How managers' emotion regulation behaviors mobilize resources for their firms. Strategic Management Journal, 40(1), 28-54. https://doi.org/10.1002/smj.2971

Jalonen, K., Schildt, H., \& Vaara, E. (2018). Strategic concepts as micro-level tools in strategic sensemaking. Strategic Management Journal, 39(10), 2794-2826. https://doi.org/10.1002/smj.2924

Kahneman, D. (2011). Thinking fast and slow. New York: Farrar, Straus and Giroux.

Khan, O., Daddi, T., \& Iraldo, F. (2020). Microfoundations of dynamic capabilities: Insights from circular economy business cases. Business Strategy and the Environment, 29(3), 1479-1493. https://doi.org/10.1002/bse.2447

Krackhardt, D. (1990). Assessing the political landscape: Structure, cognition, and power in organizations. Administrative Science Quarterly, 35, 342-369. https://doi.org/10.2307/2393394

Kunc, M. H., \& Morecroft, J. D. W. (2010). Managerial decision making and firm performance under a resource-based paradigm. Strategic Management Journal, 31(11), 1164-1182. https://doi.org/10.1002/smj.858

Larrick, R. P., \& Feiler, D. C. (2015). Expertise in decision making. In G. Keren, \& G. Wu (Eds.), The Wiley Blackwell handbook of judgment and decision making. Malden: Wiley Blackwell.

Levine, S. S., Bernard, M., \& Nagel, R. (2017). Strategic intelligence: The cognitive capability to anticipate competitor behavior. Strategic Management Journal, 38(12), 2390-2423. https://doi.org/10.1002/smj.2660

Levinson, S. C. (1995). Interactional biases in human thinking. In E. N. Goody (Ed.), Social intelligence and interaction: Expressions and implications of the social bias in human intelligence. Cambridge: Cambridge University Press.

MacLean, D., \& MacIntosh, R. (2015). Planning reconsidered: Paradox, poetry and people at the edge of strategy. European Management Journal, 33(2), 72-78. https://doi.org/10.1016/j.emj.2015.02.003

MacMillan, I. C., \& Guth, W. D. (1985). Strategy implementation and middle management coalitions (pp. 233-254). Pennsylvania: Wharton School of the University of Pennsylvania, Snider Entrepreneurial Center.

March, J. G., \& Simon, H. A. (1958). Organizations. Wiley: New York.

Nayak, A., Chia, R., \& Canales, I. (2019). Non-cognitive microfoundations: Understanding dynamic capabilities as idiosyncratically refined sensitivities and predispositions. Academy of Management Review. Epub ahead of print 20 January 2019. https://doi.org/10.5465/amr.2016.0253

Ocasio, W., \& Joseph, J. (2018). The Attention-Based View of Great Strategies. Strategy Science, 3(1), 289-294. https://doi.org/10.1287/stsc.2017.0042

Peteraf, M., \& Reed, R. (2007). Managerial discretion and internal alignment under regulatory constraints and change. Strategic Management Journal, 28(11), 1089-1112. https://doi.org/10.1002/smj.628 
Pezeshkan, A., Fainshmidt, S., Nair, A., Frazier, M. L., \& Markowski, E. (2016). An empirical assessment of the dynamic capabilities-performance relationship. Journal of Business Research, 69(8), 2950-2956. https://doi.org/10.1016/j.jbusres.2015.10.152

Powell, T. C., Lovallo, D., \& Caringal, C. (2006). Causal ambiguity, management perception, and firm performance. Academy of Management Review, 31(1), 175-196. https://doi.org/10.5465/amr.2006.19379630

Rahmandad, H., \& Repenning, N. (2016). Capability erosion dynamics. Strategic Management Journal, 37(4), 649-672. https://doi.org/10.1002/smj.2354

Richmond, V. P., \& McCroskey, J. C. (1990). Reliability and separation of factors on the assertiveness-responsiveness scale. Psychological Reports, 67(2), 449-450.

Salvato, C., \& Rerup, C. (2011). Beyond collective entities: Multilevel research on organizational routines and capabilities. Journal of Management, 37(2), 468-490. https://doi.org/10.1177/0149206310371691

Schilke, O., Hu, S., \& Helfat, C. E. (2018). Quo vadis, dynamic capabilities? A content-analytic review of the current state of knowledge and recommendations for future research. Academy of Management Annals, 12(1), 390-439. https://doi.org/10.5465/annals.2016.0014

Schilling, M. A. (2018). The cognitive foundations of visionary strategy. Strategy Science, 3(1), 335-342. https://doi.org/10.1287/stsc.2017.0044

Simons, D. J., \& Chabris, C. F. (1999). Gorillas in our midst: Sustained inattentional blindness for dynamic events. Perception, 28(9), 1059-1074. https://doi.org/10.1068/p281059

Souza, E. M., \& Forte, S. H. A. C. (2019). A contribution to the theoretical structure for cognitive dynamic capability. Revista de Administração Mackenzie, 20(4), 1-29. https://doi.org/10.1590/1678-6971/eramr190171

Stanislaw, H., \& Todorov, N. (1999). Calculation of signal detection theory measures. Behavior Research Methods, Instruments, \& Computers, 31(1), 137-149. https://doi.org/10.3758/BF03207704

Stanovich, K. E. (1999). Who is rational? Studies of individual differences in reasoning. New York: Psychology Press.

Stanovich, K. E., \& West, R. F. (1997). Reasoning independently of prior belief and individual differences in actively open-minded thinking. Journal of Educational Psychology, 89(2), 342-357. https://doi.org/10.1037/0022-0663.89.2.342

Stanovich, K. E., \& West, R. F. (2000). Individual differences in reasoning: Implications for the rationality debate?. Behavioral and Brain Sciences, 23(5), 645-665. https://doi.org/10.3758/BF03207704

Stefano, G., \& Gutierrez, C. (2019). Under a magnifying glass: On the use of experiments in strategy research. Strategic Organization, 17(4), 497-507. https://doi.org/10.1177/1476127018803840

Stroop, J. R. (1935). Studies of interference in serial verbal reactions. Journal of Experimental Psychology, 18(6), 643:662.

Suddaby, R., Coraiola, D., Harvey, C., \& Foster, W. (2020). History and the micro-foundations of dynamic capabilities. Strategic Management Journal, 41(3), 530-556.

Teece, D. J. (2007). Explicating dynamic capabilities: the nature and microfoundations of (sustainable) enterprise performance. Strategic Management Journal, 28(13), 1319-1350.

Teece, D. J. (2014). A dynamic capabilities-based entrepreneurial theory of the multinational enterprise. Journal of International Business Studies, 45(1), 8-37. https://doi.org/10.1002/smj.3058

Teece, D., \& Pisano, G. (1994). The dynamic capabilities of firms: an introduction. Industrial and Corporate Change, 3(3), 537-556. https://doi.org/10.1007/978-3-540-24748-7_10

Walsh, J. P., \& Ungson, G. R. (1991). Organizational memory. The Academy of Management Review, 16(1), 57-91. https://doi.org/10.5465/amr.1991.4278992

Wang, C. L., \& Ahmed, P. K. (2007). Dynamic capabilities: A review and research agenda. International Journal of Management Reviews, 9(1), 31-51. https://doi.org/10.1111/j.1468-2370.2007.00201.x

Wang, C., \& Hu, Q. (2020). Knowledge sharing in supply chain networks: Effects of collaborative innovation activities and capability on innovation performance. Technovation, 94, 102010-102020. https://doi.org/10.1016/j.technovation.2017.12.002 
Warner, K. S. R., \& Wäger, M. (2019). Building dynamic capabilities for digital transformation: An ongoing process of strategic renewal. Long Range Planning, 52(3), 326-349. https://doi.org/10.1016/j.lrp.2018.12.001

Weber, R. A., \& Camerer, C. F. (2003). Cultural conflict and merger failure: An experimental approach. Management Science, 49(4), 400-415. https://doi.org/10.1287/mnsc.49.4.400.14430

Winter, S. G. (2003). Understanding dynamic capabilities. Strategic Management Journal, 24(10), 991-995. https://doi.org/10.1002/smj.318

Wollersheim, J., \& Heimeriks, K. H. (2016). Dynamic capabilities and their characteristic qualities: insights from a lab experiment. Organization Science, 27(2), 233-248. https://doi.org/10.1287/orsc.2016.1053

Wu, H., Chen, J., \& Jiao, H. (2016). Dynamic capabilities as a mediator linking international diversification and innovation performance of firms in an emerging economy. Journal of Business Research, 69(8), 2678-2686. https://doi.org/10.1016/j.jbusres.2015.11.003

Younge, K. A., Tong, T. W., \& Fleming, L. (2015). How anticipated employee mobility affects acquisition likelihood: Evidence from a natural experiment. Strategic Management Journal, 36(5), 686-708. https://doi.org/10.1002/smj.2237

\section{Copyrights}

Copyright for this article is retained by the author(s), with first publication rights granted to the journal.

This is an open-access article distributed under the terms and conditions of the Creative Commons Attribution license (http://creativecommons.org/licenses/by/4.0/). 